\title{
Determination of Manganese in Tap Water by a New Extraction-Photometric Method
}

\author{
N. Kh. Rustamov, G. G. Abbasova \\ ANAS Institute of Chemical Problems Named after Acad. M.F.Nagiyev, Baki, Azerbaijan \\ Email: veliyeva_g@mail.ru
}

Received 5 February 2014; revised 7 March 2014; accepted 15 March 2014

Copyright (C) 2014 by authors and Scientific Research Publishing Inc.

This work is licensed under the Creative Commons Attribution International License (CC BY). http://creativecommons.org/licenses/by/4.0/

(c) (i) Open Access

\section{Abstract}

The heteroligand complex of manganese with 1,10-phenantroline and o-nitrobenzolazosalicylic acid has been investigated by spectrophotometric method. The condition of complexing and extraction, physical-chemical and analytical characteristics of this complex have been found. Complex formation is observed in the $\mathrm{pH}$ range 5 - 11. Extraction constant was found as $5.3 \times 10^{12}$, stability constant was found as $\lg \beta_{\mathrm{K}}=9.03 \pm 0.03$. Molar absorptivity is $\varepsilon=(1.36 \pm 0.08) \times 10^{4} \mathrm{l} \cdot \mathrm{g}^{-1} \cdot \mathrm{cm}^{-1}$. Beer's law is obeyed in the range of $1.0-22.5 \mu \mathrm{kg}$ manganese (II). The extraction-photometric methods of manganese determination have been worked out. The influence of diverse ions on determination of manganese (II) has been studied. The proposed method was applied successfully to determine amount of manganese in tap water.

\section{Keywords}

Water; Extraction-Photometric Determination; Complexing; Manganese; 1,10-Phenantroline; Chromogenic Organic Reagent

\section{Introduction}

Manganese is considered to be the $12^{\text {th }}$ most abundant element in the biosphere. Its concentration in earth crust reaches as high as $\mathbf{0 . 0 9 8 \%}$. It is widely distributed in soil, water, sediment and biological materials. Manganese has cumulative properties. Due to this accumulating in the organism chronic manganese excess affects the central nervous system, with the symptoms resembling those of Parkinson's disease [1] [2].

Various methods for the determination of manganese with chromogenic organic reagents have been reported. The reagents suggested for determination of manganese include: toluidine blue [3], Mordant brown 33 [4], phenoxazine [5], eosin [6]. Along with the advantages of these methods, there are also disadvantages. Although molar absorptivity in [3] is high, but constant stability is very little. In [4], molar absorptivity is very less than in 
current method.

In the literature there is data on the use of o-nitrobenzolazosalicylic acid for determination of nickel, zinc, ferrum, cobalt [7]-[10]. But no data about determination of manganese with o-nitrobenzolazosalicylic acid can be found in the literature.

The heteroligand complex of manganese (II) has been investigated with 1,10-phenantroline (Phen) from aromatic diamines and with o-nitrobenzolazosalicylic acid (oNBASA) from chromogenic organic reagents and the new rapid, simple and sensitive extraction-photometric method of manganese determination with these reagents have been worked out by us.

\section{Materials and Methods}

\subsection{Instruments}

Absorption measurements were collected on a CФ 46 "LOMO” (Leningradskoe Optiko-Mexanicheskoe Obedinenie) spectrophotometer or КФК-3 “ZOMZ” (Zaqorskiy Optiko-Mexanicheskiy Zavod) photoelectrocolourymeter using $1 \mathrm{~cm}$ cuvette. The pH-meter EV-74 (Q. Qomel, Zavod Izmeritelniypriborov) is used for pH measurements.

\subsection{Reagents}

Stock solution of $1.52 \times 10^{-2} \mathrm{M}$ manganese (II) was prepared from $\mathrm{MnCl}_{2} \cdot 4 \mathrm{H}_{2} \mathrm{O}$ salt with qualification "p.f.a." (pure for analysis) and quantity of manganese standardized gravimetrically with o-phenantroline and $\mathrm{SCN}^{-}$[11]. Working solution of $4.5 \times 10^{-4} \mathrm{M}$ manganese (II) was prepared by dilution of stock solution with deionized water. Solution of oNBASA with $5 \times 10^{-3} \mathrm{M}$ concentration was prepared by dissolving the required amount in water, while $\mathrm{pH}$ of this water was arrived to 12 , previously. Because, $\mathrm{pK}_{1}=3.16$ and $\mathrm{pK}_{2}=12.30$ for oNBAST. Solution of Phen with $1 \times 10^{-2} \mathrm{M}$ concentration was prepared by dissolving the required amount of preparate which was productioned in firm "Chemapol" in ethanol: water (50:50, by volume). Universal or borate buffer solutions $\left(\mathrm{H}_{3} \mathrm{BO}_{3}+\mathrm{HCl}, \mathrm{H}_{3} \mathrm{BO}_{3}+\mathrm{NaOH}\right)$ or $0.1 \mathrm{M} \mathrm{CH}_{3} \mathrm{COOH}$ and $1 \mathrm{NNaOH}$ solutions were used for obtaining appropriate $\mathrm{pH}$.

\subsection{Procedure}

Appropriate amount of solutions of Phen and oNBASA have been added to the definite amount of solution of manganese (II) in test-tube with stoppers or in separatory funnel. Then total volume have been diluted to $10 \mathrm{ml}$ by adding of different (pH 5.0 - 11.0) buffer solution. The mixture has been shaked for 1 minute with adding of $5 \mathrm{ml}$ solvent (chloroform). Colored extract (organic phase) has been transferred to the cuvette when the phases separated and absorbance has been measured relative to the water. The analogical experiment has been carried out without manganese and absorbance of the extract of reagent has been measured also relative to the water.

\section{Results and Discussion}

Investigations show that the derivatives of salicylic acid form colored complexes with transition metals [7]-[10] and this can be used in developing an extraction-photometric methods for the determination of these metals, also of manganese (II).

\subsection{Condition of Complexing and Spectral Characteristics}

The absorption spectra of chromogenic organic reagent and complex of manganese with Phen and oNBASA obtained in the $\mathrm{pH}$ range 5.0 - 11.0 of the aqueous phase showed that manganese (II) with Phen and oNBASA forms a complex one composition. The absorption spectra of solutions of reagent and the complex show that the maximum absorbance takes place at $\mathrm{pH} 10$ (Figure 1) and wavelength of $370 \mathrm{~nm}$ have been selected for the present work (Figure 2).

The influence of the concentration of Phen and oNBASA was studied. The optimal concentration of Phen and oNBASA for formation of the complex was found to be $6 \times 10^{-4} \mathrm{M}$ and $2.5 \times 10^{-4} \mathrm{M}$, respectively.

Excess amount of Phen and oNBASA does not affect the formation and extraction of the complex. Because, in the condition of complexing the carboxyl group of the chromogenic organic reagent is ionized and charged 


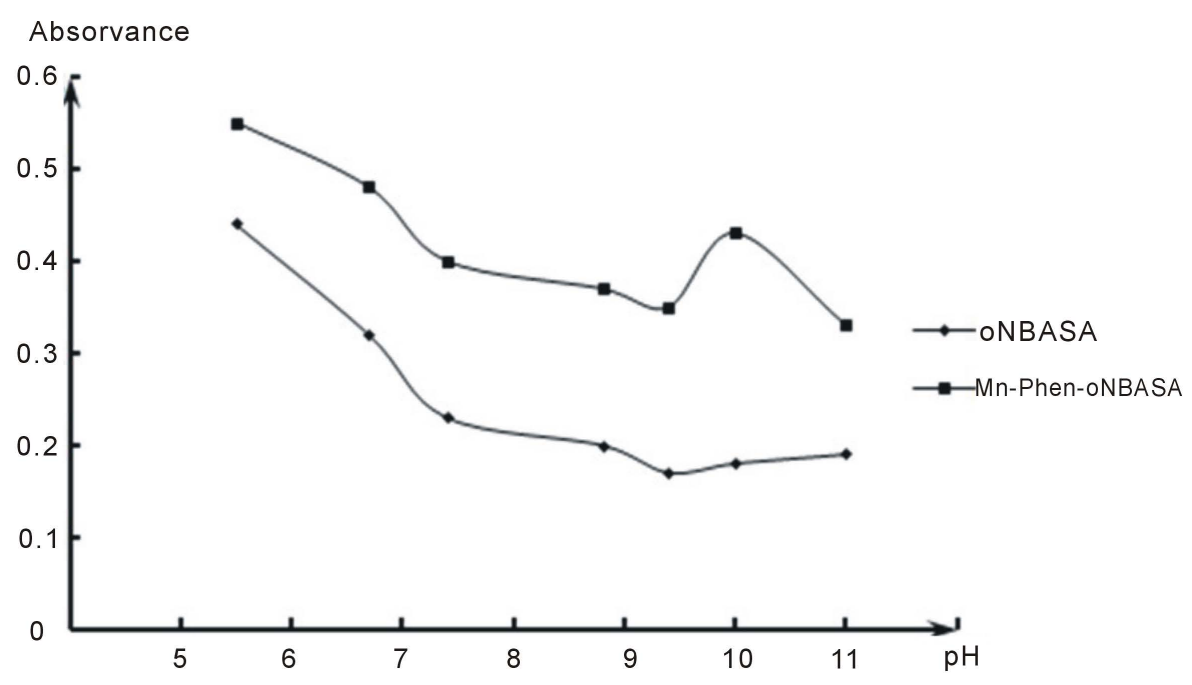

Figure 1. The influence of $\mathrm{pH}$ of the aqueous phase in the formation and extration of the complex of manganese(II) with Phen and Onbasa. $\left(C_{\mathrm{Mn}}^{2+}=2.23 \times 10^{-5} \mathrm{M}, \mathrm{C}_{\mathrm{Phen}}=2 \times 10^{-4} \mathrm{M}\right.$, $\left.\mathrm{C}_{\text {oNBASA }}=1.5 \times 10^{-4} \mathrm{M}, \mathrm{K} \Phi \mathrm{K}-3, \lambda=400 \mathrm{~nm}\right)$.

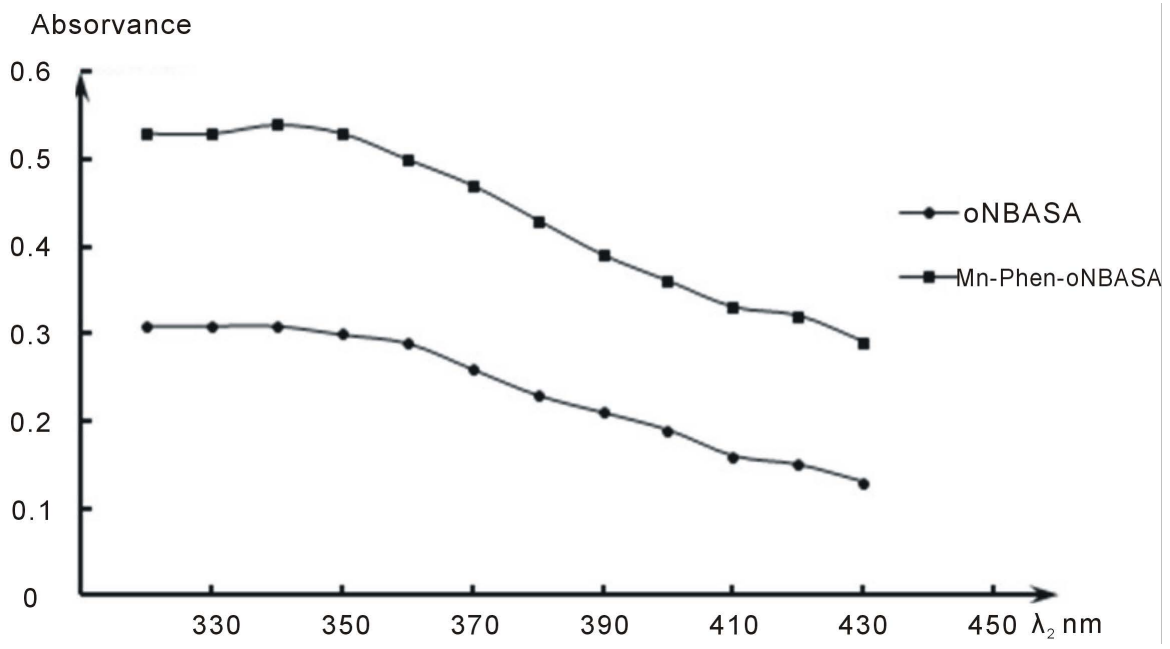

Figure 2. Absorption spectra of extract of $\mathrm{Mn}^{2+}$-Phen-Onbasa and Onbasa $\left(C_{\mathrm{Mn}}^{2+}=2.23 \times 10\right.$ $\left.{ }^{-5} \mathrm{M}, \mathrm{C}_{\text {Phen }}=2 \times 10^{-4} \mathrm{M}, \mathrm{C}_{\mathrm{oNBASA}}=1.5 \times 10^{-4} \mathrm{M}, \mathrm{pH}=10, \mathrm{C} \Phi-46, \mathrm{l}=1 \mathrm{~cm}\right)$.

form is preferably in the aqueous phase. The heterolig and complex of manganese (II) with Phen and oNBASA was extracted with chloroform and 1,2-dichloroethane. Optimal volume of aqueous and organic phase was found to be 25 - 50 and $5 \mathrm{ml}$, respectively. Mn-Phen-oNBASA complex is formed immediately after adding the reagents and extraction equilibrium is achieved by shaking up 1 minute.

The sequence of reagents to be added does not affect the complex formation and extraction. The intensity of color of the complex does not change depending on time and stable during the day.

\subsection{Content of Complex}

The stoichiometric coefficients of the complexing were established. The molar ratio Mn:Phen:oNBASA was proved by the method of straight line and crossing the lines [12]. The results for the light absorption of the extracts at $370 \mathrm{~nm}$ showed that the complex was formed at a ratio Mn:Phen:oNBASA = 1:2:2. By the method of V. A. Nazarenko [13] was established that the complexing form of manganese are the ions $\mathrm{Mn}^{2+}$. The same amount of complex two times was extracted consistently and extraction percentage was found: $98.76 \%$. 
Extraction constant was found as $5.3 \times 10^{12}$, stability constant was found as $\lg \beta_{\mathrm{K}}=9.03 \pm 0.03$.

By the method of Komar [12] was found molar absorptivity is $\varepsilon=(1.36 \pm 0.08) \times 10^{4} \mathrm{l} \cdot \mathrm{g}^{-1} \cdot \mathrm{cm}^{-1}$. Beer's law is obeyed in the range of $1.0-22.5 \mu \mathrm{kg}$ manganese (II). Equation of the calibration curve was based to be $\mathrm{A}=$ $0.038 \mathrm{C}+0.01$. Calibration curve are presented in Figure 3. The relative standard deviation for 5 determinations with 1.0-5.0-10.0-20.0 $\mu \mathrm{kg}$ of manganese(II) of the method is $\pm(1.69-2.19) \%$. The detection limit of manganese was found as $0.004 \mu \mathrm{kg} \cdot \mathrm{ml}^{-1}$. Statistical results are presented in Table 1 .

\subsection{Effect of Diverse Ions}

In order to assess the usefulness of the proposed method the influence of strange ions on the extraction-photometric determination of manganese was studied. The tolerance of the method of foreign ions was investigated with solutions containing $10 \mu \mathrm{kg}$ Mn (II) per $25 \mathrm{ml}$ and various amounts of foreign ions. Mn (II) was determined as $\mathrm{Mn}(\mathrm{Phen})_{2}(\mathrm{oNBASA})_{2}$ under the optimum conditions as described in the experimental procedure. The determination of manganese was possible in the presence of $\mathrm{Li}$ (I), $\mathrm{Na}$ (I), $\mathrm{K}$ (I), Ca (II), $\mathrm{Sr}$ (II), Ba (II), Cd (II), $\mathrm{Hg}$ (II), Al (III), Ti (IV), Zn (II), V (V), Cr (III), Mo (VI), Ni (II), Pb (II), As (V), Mg (II), Bi (III), In (III), Ge (IV). But Co (II), Zn (II), Cu (II), Fe (III), Ag (I) ions were influenced on the extraction-photometric determination of manganese (II).

\subsection{Determination of Manganese (II) in Tap Water}

Water sample was taken in the flask $2 \mathrm{l}$ and was evaporated to dryness. Dry residue was dissolved in a buffer solution with $\mathrm{pH} 10$ and by filtering was transferred to a $50 \mathrm{ml}$ flask. $2 \mathrm{ml}$ aliquot part was transferred to the separatory funnel or test-tube. $0.6 \mathrm{ml}$ Phen and $0.5 \mathrm{ml}$ oNBASA was added. Then was diluted by the same buffer solution to $10 \mathrm{ml}$ and was extracted with $5 \mathrm{ml}$ chloroform for 1 minute. Absorbance was measured in CФ 46 in the cuvette of $1 \mathrm{~cm}$ when the phases separated. Amount of manganese was determined from the calibration graph.The results were compared with the results of the determination method of manganese wich referenced in [4]: $0.02 \pm 0.01$.Amount of manganese have been determined in tap water by the proposed method: $0.018 \pm$ $0.009 \mu \mathrm{kg} / \mathrm{ml}$. Comparison of methods of manganese is presented in Table 2.

\section{Conclusion}

At the first time, the heteroligand complex of manganese (II) has been investigated with 1,10-phenantroline

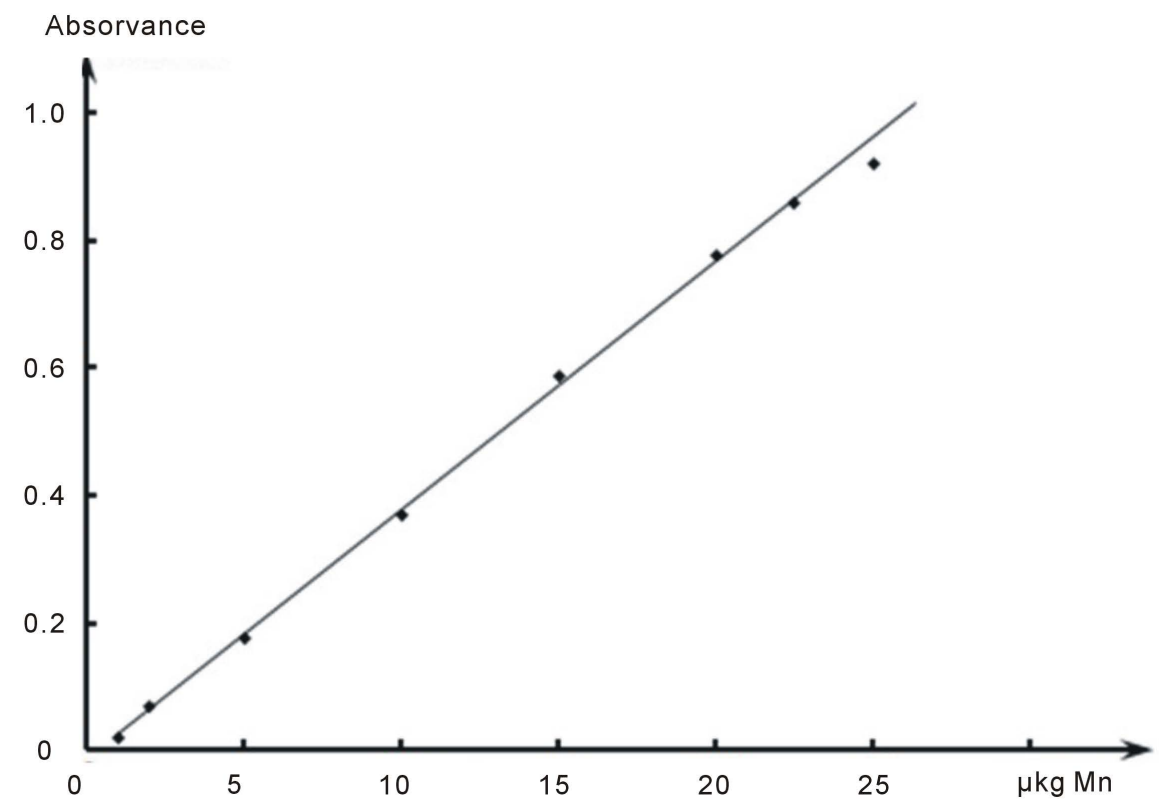

Figure 3. Calibration curve of determination of manganese with Phen and oNBASA. 
Table 1. Statistical results of determionation of manganese with Phen and oNBASA $(n=5, p=0.95)$.

\begin{tabular}{cccccccc}
\hline Taken manganese (II), $\mu \mathrm{kg}$ & $X$ & $\mathrm{~S}^{2} \cdot 10^{3}$ & $\mathrm{~S}_{X} \cdot 10^{2}$ & $\mathrm{~S}_{\mathrm{r}} \cdot 10^{2}$ & $S_{\bar{X}} \cdot 10$ & $\frac{\varepsilon_{\alpha}}{\bar{X}} \cdot 100$ & $\bar{X} \pm \varepsilon_{\alpha}$ \\
\hline 1 & 1.01 & 1.06 & 3.25 & 3.22 & 0.14 & 3.5 & $1.01 \pm 0.03$ \\
2 & 2.02 & 0.3 & 1.67 & 0.83 & 0.08 & 1.01 & $2.02 \pm 0.02$ \\
5 & 5.04 & 9.25 & 9.62 & 1.91 & 0.43 & 2.08 & $5.04 \pm 0.10$ \\
10 & 10.04 & 43 & 20.7 & 2.06 & 0.93 & 2.26 & $10.04 \pm 0.22$ \\
12 & 12.04 & 173 & 41.59 & 3.45 & 1.86 & 3.78 & $12.04 \pm 0.45$ \\
15 & 15.08 & 29.6 & 17.20 & 1.14 & 0.77 & 1.25 & $15.08 \pm 0.18$ \\
20 & 20.08 & 102 & 2.04 & 0.1 & 1.43 & 1.74 & $20.1 \pm 0.34$ \\
\hline
\end{tabular}

Table 2. Comparison determination methods of manganese with proposed and referenced.

\begin{tabular}{|c|c|c|c|c|}
\hline \multirow{2}{*}{$\begin{array}{l}\text { Determination methods of } \\
\text { manganese }\end{array}$} & \multirow{2}{*}{$\begin{array}{c}\text { Amount of manganese } \\
\mu \mathrm{kg}\end{array}$} & \multicolumn{2}{|c|}{ Manganese has been found } & \multirow{2}{*}{ Deviation \% } \\
\hline & & $\mu \mathrm{kg}$ & $\%$ & \\
\hline \multirow{7}{*}{ Proposed method } & 1 & 1.04 & 104 & +4.0 \\
\hline & 1.5 & 1.52 & 101.3 & +1.3 \\
\hline & 3 & 3.05 & 101.7 & +1.7 \\
\hline & 4 & 3.98 & 99.6 & -0.4 \\
\hline & 5 & 4.95 & 99.0 & -1.0 \\
\hline & 7 & 7.04 & 100.6 & +0.6 \\
\hline & 10 & 10.05 & 100.5 & +0.5 \\
\hline \multirow{7}{*}{ Referenced method [4] } & 2.5 & 2.78 & 111.2 & +11.2 \\
\hline & 3.0 & 3.20 & 106.7 & +6.7 \\
\hline & 3.5 & 3.69 & 105.4 & +5.4 \\
\hline & 4.0 & 3.72 & 93 & -7 \\
\hline & 5.0 & 4.70 & 94 & -6 \\
\hline & 7.0 & 7.35 & 105 & +5 \\
\hline & 10.0 & 10.3 & 103 & +3 \\
\hline
\end{tabular}

(Phen) and o-nitrobenzolazosalicylic acid (oNBASA) from chromogenic organic reagents. The new rapid, simple and sensitive extraction-photometric method of manganese determination with these reagents has been worked out and applied to determination of manganese (II) in tap water by us.

\section{References}

[1] Nadaska, G., Lesny, J. and Michalik, I. (2012) Environmental Aspect of Manganese Chemistry. http://heja.szif.hu/ENV/ENV-100702-A/env100702a.pdf

[2] Marbaniang, D.G. (2012) Spectrophotometric Determination of Manganese in Ground Water in Shillong City Using Bismuthate Oxidation Method. International Journal of Environmental Protection, 2, 22-26.

[3] Kostova, D. (2010) Determination of Manganese by a New Spectrophotometric Method Using Toluidine Blue. Journal of Analytical Chemistry, 65, 163-167. http://dx.doi.org/10.1134/S1061934810020103

[4] Seleim, M.M., Abu-Bakr, M.S., Hashem, E.Y. and El-Zohry, A.M. (2009) Spectrophotometric Determination of Manganese (II) with Mordant Brown 33 in the Presence of Tween 20 in Some Foods. Canadian Journal of Analytical Sciences and Spectroscopy, 54, 93-101.

[5] Mghimi, M., Syed, A.A., Al-Okab, R.A. and Taghartapeh, M.R. (2010) Application of Electrophilic Coupling Reaction as a Novel Spectrophotometric Methods for the Determination of Manganese. International Conference on Biology, Environment and Chemistry, 337-340.

[6] Rauf, M.A., Ikram, M. and Ahmad, M. (2002) Spectrophotometric Studies of Ternary Complexes of Vanadyl, Manganese and Iron with o-Phenantroline and Eosin. Journal of Trace and Microprobe Techniques, 20, 171-180. http://dx.doi.org/10.1081/TMA-120003722

[7] Rustamov, N.Kh., Mustaphayev, N.M. and Rustamova, U.N. (2004) Photometric and Extraction-Photometric Determination of Nickel with Azoderivative Salicylic Acid and Ligands with N-, P-, O- . Journal of Chemistry and Chemical Technology, 47, 15-20. 
[8] Rustamov, N.Kh. and Bayramova, T.D. (2005) Heteroligand Complexes of Zinc with 1,10-Phenanthroline and Alizarine Yellow R. Azerbaijan Chemical Journal, 4, 97-99.

[9] Rustamov, N.Kh., Aliyeva, A.A. and Agamaliyeva, M.M. (2003) Azoderivatives of Salicylic Acid in the Presence of o-Phenanthroline as an Extraction Reagent for the Photometric Determination of Fe(III). Azerbaijan Chemical Journal, 2, 54-57.

[10] Rustamov, N.Kh., Abbasova, G.G. and Mustaphayev, N.M. (2011) Extraction-Photometric Determination of Kobalt 4, 7-Difenil-1,10-Phenantroline and Alizarine Yellow R. Journal of Chemical Problems, 3, 495-497.

[11] Lavrukhina, A.K. and Yukina, L.V. (1974) Analytical Chemistry of Manganese. Nauka, Moskow, 315.

[12] Bulatov, M.I. and Kalinkin, I.P. (1976) Practical Manual of Photocolorymetric and Spectrophotometric Methods Analysis.

[13] Nazarenko, V.A. (1969) Proceedings of the Committee on Analytical Chemistry. Nauka, Moscow, 12. 